\title{
Cohesiveness in Informal Written Text, Song Lyrics
}

\author{
Dian Nauwala Putri ${ }^{1, *}$ \\ ${ }^{1}$ Department of English Language Studies, Universitas Hasanuddin, Makassar, Indonesia \\ *dianwlpt@gmail.com
}

\begin{abstract}
Nowadays, people communicate with each other in different ways, and there is a message given through the speech. Songs lyrics are some examples of written discourses that have the textual function for communication. This research concerns written discourse in the form of song lyrics sung and written by Bruno Mars, with coherence devices to see the song's cohesiveness. The design of this research was a descriptive study by using a qualitative approach. The source data is fifteen songs from three different albums titled "Doo-woops \& Hooligans (2010)", "Unorthodox Jukebox (2012)", and "24K Magic (2016)" by Bruno Mars. The technique of analysis involved categorization, abstraction, and coding the text. After identifying the data, the writer carried out investigator triangulation to validate the data by discussing the findings. The result showed the cohesiveness found in the text by using Oshima and Hogue theory about coherence. From analysis, it was found two things related to cohesive devices. First, the use of coherence devices, which consist of repeated keywords, consistent pronouns, transition signals, and there is no logical order found in the song lyric. Second, the findings of coherence devices used in the lyrics are proved that the informal written text take the contribution to delivered the cohesiveness information. It means coherence devices are taking part in the continuity and clarity of the lyrics. Therefore, it can be concluded that the existence of cohesion and coherence relation in the lyrics takes the contribution and also sets up the context for the interpretation of the meaning of the song.
\end{abstract}

Key words: Bruno Mars, coherence, cohesive, lyrics.

\section{Introduction}

Song is a short piece of music through the melody and vocals. Songs are also useful in learning English. Songs are one type of listening activity that essential part of growing and learning [1]. In learning English through listening activity, teachers mostly use songs to teach the students about the conception of language fun to keep them excited. Song can be useful in teaching for young learners because they are naturally musical interested. One of the part of the song is lyric [2]. Lyric is the words of a song that make a song beautiful. The lyric addresses the reader directly, interpreted his or her feeling, state of mind, and perception.

Based on the explanation that mentions above, it inspired the writer to study song. The writer wanted to study songs but from a linguistic point of view. It means the study was about how a song can produce meaning or purposes that perform a unity with the view of linguistic. The studies about language related to meaning and form or semantically relationship and correlation are called discourse analysis. To create a discourse, it is must connect the cohesion and coherence that need the ability to use the right texts to convey the information through the songs lyric would be 
understandable to the listeners. As Halliday and Hasan state, "a text or a paragraph that uses cohesion and coherence must be good writing." [3]. That means both cohesion and coherence are essential properties in the text because they will give the text unity by connect the words through the melody in creating unity between the text. Therefore, the writer wanted to understand the kinds and the functions of cohesion and coherence used in Bruno Mars' songs. The writer has chosen Bruno Mars's song in this study because he is one of the top pop music's premier songwriters of all time.

\section{Theoretical Reviews}

Coherence is taken from the Latin verb cohere that means "stick together". Coherence is a coherence passage of discourse in two regards [4]. It is coherence concerning the context of the situation, and therefore consistent in a register. Oshima and Hogue state that coherence is achieved when the sentences and ideas are connected and flow smoothly [4]. It means between words, sentences, and paragraphs should logically help connect and focus the ideas throughout the text. Coherence involves the connection of text, such as the connection of words, sentences, and paragraphs. Coherence is divided four ways to analyze text with coherence if it represents repeating key nouns, using pronouns, transition signals, and logical order [4].

\section{- Repeating key nouns}

Repeating key nouns are the easiest way to achieve coherence through the text. Repeating key nouns (keywords) helps the readers remain focused and headed in the right direction [4]. Through the use of repeating key nouns, the words, sentences, or paragraphs need to connect. For example: "Gold, a precious metal, is prized for two important characteristics. First of all, gold has a lustrous beauty that is resistant to corrosion...". The word "gold" as the key noun is repeated in the second sentence.

- Using pronouns

Using pronouns is used to link or connect sentences by referring to nouns and pronouns. Oshima and Hogue quoted that "in the use of pronouns in the text, the writer needs to make sure that it is used the same person and number throughout the word, sentence, or paragraph [4]. Don't change 'you' to 'he' or 'she' (change of person) or from 'he' to 'they' (change of number)". Therefore, the use of pronouns should be consistent to refers to the previous nouns or pronouns. For example: "Furthermore, aspiring Olympians must train rigorously for many years. For the most demanding sports, they train several hours a day". The pronoun "they" was repeated 2 times which refers to the "Olympians".

- Using transition signal

As Oshima and Hogue proposed, "transition signals are like traffic marks, they tell the readers when to go forward, turn around, slow down, and stop" [4]. It means the writer tells the reader when they were giving a similar idea (similarly, and, in addition), an opposite idea (but, on the other hand, in contrast), an example (for example), a result (therefore, as a result), or a conclusion (in conclusion). Therefore, transition signals are used in connecting words or phrases that strengthen the internal cohesion and coherence of the writing. It gives the text coherence because it guides the reader to know the text's meaning through one idea to the next. For example: "In warm climate zones, water evaporates rapidly: therefore, the concentration of salt is greater". The word "therefore" is the transition signal.

- Logical order

To achieve coherence, it needs to arrange their writing ideas in logical order depending on the topic and the text's purpose. For example: "... First of all, gold has a lustrous beauty that is resistant to corrosion. Therefore, it is suitable for jewelry, coins, and ornamental purposes...". The word "first of all" uses to discusses gold's beauty, and the second word "therefore" uses to discusses gold's utility.

\section{Methodology}

\section{Design}

This study used descriptive qualitative study because it needs data, analysis, and interpretation of the meaning. This study would describe descriptively based on the types of coherence by selecting, classifying, and describing (by counting coherence) used in the data.

\section{Data Source}

The data of this research are only words, phrases, or sentences in lyrics of Bruno Mars's songs, which contain the cohesive devices. The lyrics are chosen randomly by using SRS (Simple Random Sampling) technique. Moore and McCabe define a simple random sample (SRS) as a set of individuals from a population with an equal chance to be the sample selected, cited from utexas.edu/users/mks/statmistakes/SRS.html. The result number of the song titles 
using this technique took 15 songs from three albums to be analyzed. The following are Bruno Mars' song lyric that has taken as the data; they are: Grenade, Runaway Baby, The Lazy Song, Talking to The Moon, Count On Me (Doo-wops \& Hooligans albums 2010), Treasure, Moonshine, When I Was Your Man, Natalie, Money Make Her Smile (Unorthodox Jukebox albums 2012), 24K Magic, Chunky, That's What I Like, Finesse, and Too Good to Say Goodbye (24K Magic albums 2016).

\section{Instrument}

The key instrument of this study is the writer herself. She uses her skills and spends a great deal of time collecting, understanding, and analyzing the songs lyric to identify coherence expressed in Bruno Mars's songs' lyrics. To give a clear explanation of the study, the writer uses many sources like books, libraries, and the internet to support her study.

\section{Data Collection}

In this study, the writer collected the data mainly from the songs of Bruno Mars. In collecting data, the writer did the following activities, they are: taking the samples of the lyrics by applying the SRS method, downloaded the lyrics of Bruno Mars's songs, numbering the fifteen songs, listening and reading to the songs lyric thoroughly and repeatedly will be analyzed.

\section{Data Analysis}

After the data are collected, the data are analyzed with the content analysis classified into several steps, they are: categorization, abstraction, coding the text, and results [5]. To avoid bias, the writer drawing her conclusion, verification is needed to be done. The verification would be done through the triangulation process with investigator triangulation. The writer consults and checks the types and functions of coherence and cohesion in her analysis with the other person of her study. Triangulation is very useful to find the validity of the research. The writer invited the second investigator to validity the data.

\section{Findings and Discussion}

Based on the analysis, the results of the used of cohesion and coherence in the lyrics of Bruno Mars' songs. The writer took 15 songs lyric from three albums of Bruno Mars released from 2010 until 2016 and found 1488 words as the data. The findings below describe how the songs lyric producing coherence types. The coherence of the text should have cohesiveness and unity, to transfer between one verse into another verse. The writer collected and calculated the data and described each of the types through each lyric written. Furthermore, the following table shows the data on the number of occurrence and percentage of coherence types.

Table 1. Number of Occurrences of Types of Coherence In the Lyric of Bruno Mars' Songs

\begin{tabular}{ccccc}
\hline & \multicolumn{4}{c}{ Type of Cobaherence } \\
\cline { 2 - 5 } Song Lyric & $\begin{array}{c}\text { Repeating } \\
\text { Key Nouns }\end{array}$ & $\begin{array}{c}\text { Using } \\
\text { Pronouns }\end{array}$ & $\begin{array}{c}\text { Using Transition } \\
\text { Signals }\end{array}$ & $\begin{array}{c}\text { Logical } \\
\text { Order }\end{array}$ \\
\hline 1 & 0 & 52 & 14 & 0 \\
2 & 2 & 55 & 7 & 0 \\
3 & 0 & 38 & 7 & 0 \\
4 & 3 & 44 & 9 & 0 \\
5 & 2 & 34 & 12 & 0 \\
6 & 6 & 53 & 7 & 0 \\
7 & 3 & 56 & 11 & 0 \\
8 & 6 & 35 & 19 & 0 \\
9 & 0 & 67 & 18 & 0 \\
10 & 7 & 24 & 3 & 0 \\
11 & 8 & 49 & 6 & 0 \\
12 & 0 & 42 & 4 & 0 \\
13 & 8 & 91 & 26 & 0 \\
14 & 4 & 63 & 7 & 0 \\
15 & 0 & 64 & 12 & 0 \\
\hline Total & 49 & 767 & 162 & 0 \\
\hline
\end{tabular}


The table above illustrates 978 coherent in the 15 song lyric of Bruno Mars' songs. The third types of coherent appear: repeating key nouns, using pronouns, and using transition signals.

Coherence is defined principally as a feature of the text, either in linking the text (cohesion) or as the relationship among proposition in the text. Coherence is categorized into repeating keywords, using consistent pronouns, using transition signals, and using logical order. Using consistent pronouns is the most frequent type among all types of coherence. It appears 767 times. The second level is using transition signals, which occur 162 times. While repeating pronouns emerge 49 times. There is no logical order type in of coherent in the songs lyric. It is no found because it is seen from the whole text in the context of written text, whether the texts involve the logical order or not. Hence, the songs lyric analyzed in this research mostly use consistent pronouns to make the lyric verses seem reliable and unity. The coherent verse makes all the lines related smoothly within and between them. It is easy for the listeners to know the meaning of the songs lyric.

The research question was: How are the coherences found in the lyrics of Bruno Mars's songs. From the data analysis above, to achieve the fifteen songs lyric's coherence, the songwriter used to repeat the keyword, used consistent pronouns, and used transition signals. The use of consistent pronouns is the most frequent type than the other types of coherence. The less frequent type of coherence is repeated keywords. It is less frequent because to classify the keyword of the lyrics, and it needs to relate the whole text with the title of the song lyric mentioned in each verse of the lyric. A different result is found with the previous study that analyzed the concept of coherence in explanation text [6]. In her research, there found repeating keywords is the most frequently used among all types of coherence. That happens because in making a coherent paragraph in the explanation text, it must use repeating keywords to make all the sentences related smoothly and make the readers easy to move from sentence to sentence. This study has a different result because the data is also different, which explains text that consists of paragraphs with songs lyric that consist of verses. Therefore, it can be said that this research enhances the findings of the previous study with the concept of coherence.

In these texts, the dominant use to make the songs lyric coherence is consistent pronouns. It is found by the most commonly used of consistent pronouns from the first verse to the last of the songs is with the contribution of cohesive devices personal reference ' $I$ ' as the first main character and 'you' as the second main character outside the text. This finding is also different from the previous study [6]. In her study, the used of consistent pronouns are commonly expressed with the item 'it' and 'we', where the text is talked about things with the pronoun 'it' and deliver the ideas of the text with the first-person pronoun 'we' as the way to indicating the readers with the writers. And also, the other types of coherence that are used in the lyrics are used transition signals. The cohesive devices in type conjunction take the contribution to make the text classified as coherence. It is used to connect the ideas from one line to other lines to make the coherent verses of the songs lyric. This finding has the same result with the previous study [6], where both explanation text and lyric are generally used in conjunction to signal the relationship between one idea to another. Transition signals to make the text coherent are also found as the second frequent type after using consistent pronouns.

On the other side, it is difficult to find the type of logical sequence outlined with the theory of Oshima and Hogue because it appears in the written text developed by chronological order. It starts from a background of the problem, and it can be formulated at some point. Then it will be different in analyzing the written text in the form of the song lyric because the order has come from the whole verses, which are not formally written like the whole paragraphs. Therefore, there is no logical order in achieving coherence in songs lyric.

From the explanation above, the cohesive devices on lyrics were contributed to making the text coherence. It functions to refer and give the meaning of the song that the songwriter implied to the listeners. Because the song's lyrics are a kind of narrative story, the cohesion and coherence in the lyrics are for linking all narrative events together so that the song becomes meaningful and helps the listeners perceive the entire song story which wants to be told by the songwriter.

\section{Conclusion}

The writer collected data cohesive devices found in 15 songs lyric by Bruno Mars by reading all the lyrics while took notes and classified the line that contain the coherence types. The writer found the cohesive devices that contribute to the coherence of the 15 songs lyric by Bruno Mars. It contributes to the text's coherence by repeating the same keywords, using consistent pronouns, and the use of transition signals throughout the lyrics. That means using cohesive devices is functioned to make the text classified as coherence because the lyrics applied all types of coherence except logical order. Therefore, the relations of coherence in the text contribute and set up the context for interpreting the songwriter's perspective to deliver to the listeners. The writer has some suggestion for both lectures and students of English Department University, they are: For the lecturer, there is a method to make the students interested in learning the English language, especially in discourse. The method that can be used in teaching English is using songs lyric to learn the new vocabulary as the supporting media. The teacher can explain the definition of coherence, identify and find the meaning of the song through the relationship between cohesiveness in formal and informal 
written text. For student of English department, by using songs lyric as a tool of learning, they are expected to understand discourse. There are many parts of discourse analysis, and the one part of discourse analysis is coherence. This study is expected to help the students add their knowledge about coherence in analyzing the song's meaning. For the future writer, they should explore both the cohesive devices more than this present research using another theory and different objects. The next writers' suggestion to explore different text types from this research uses analyzing speech, film, talk show, or podcast, which is given the daily communication language that would be variated. Therefore, the content of data is different and will find a different discussion.

\section{References}

[1] A. Bolderston \& C. Palmer, "A brief introduction to qualitative research." Canadian Journal of Medical Radiation Technology, 37(1), 16-19. 2006

[2] J. Renkema, Discourse studies: An introductory textbook. Amsterdam: Benjamins, 1993

[3] M.A.K. Halliday \& R. Hasan, Cohesion in English. London: Longman 1, 1976.

[4] A. Oshima \& A. Hogue, Writing Academic English, $4^{\text {th }}$ ed. White Plains, NY: Pearson/Longman, 2006

[5] P. Mayring, Qualitative Content Analysis. Klagenfurt, Austria, 2014.

[6] N. A. Wachidah, An Analysis of Cohesion and Coherence In The Students' Writing Text. Salatiga: Universitas IAIN Salatiga, 2016.

[7] J. C. Catford, A Linguistic Theory of Translation. Oxford: Oxford University Press, 1965.

[8] S. Bailey, Academic Writing A Handbook for International Students. London: Routledge, 2006.

[9] N. K. Denzin, Sociological Methods: A Sourcebook, $1^{\text {st }}$ ed. New York, NY: Aldine Transaction, 2006.

[10] SA. Pejic \& N. D. Dzanic. "The Effect of Using Songs on Young Learners and Their Motivation for Learning English," An Interdisciplinary Journal, University of Tuzia, 2016. 